\title{
Omalizumab as a new therapeutic approach for children with severe asthma
}

\author{
Joanna Jerzyńska, Anna Sztafińska, Katarzyna Woicka-Kolejwa, Iwona Stelmach
}

Department of Pediatrics and Allergy, Medical University of Lodz, Poland

Head of Department: Prof. Iwona Stelmach MD, PhD

Postep Derm Alergol 2014; XXXI, 1: 45-46

DOI: $10.5114 /$ pdia.2014.40660

\begin{abstract}
Omalizumab has been shown to improve asthma control when added to a regimen of guideline-based therapy for inner-city children and adolescents, nearly eliminating seasonal peaks in exacerbation and reducing the need for other medications to control asthma. Below, we describe a case of a 17-year-old non-smoker with a history of severe asthma admitted to our clinic after unsuccessful 10-year immunotherapy. The patient fulfilled the criteria for anti-IgE therapy, he was prescribed omalizumab $600 \mathrm{mg}$ every 2 weeks. During therapy he was able to reduce his use of ICS and did not require any oral corticosteroids. He experienced an increase in his ability to exercise and noted no exacerbation of asthma symptoms. It is possible that in our patient, specific immunotherapy could be successfully continued after the initiation of omalizumab therapy.
\end{abstract}

Key words: omalizumab, severe asthma, immunotherapy.

\section{Introduction}

Omalizumab has been shown to improve asthma control when added to a regimen of guideline-based therapy for inner-city children and adolescents, nearly eliminating seasonal peaks in exacerbation and reducing the need for other medications to control asthma [1-5]. Omalizumab might also be a treatment option in patients who fail to achieve an optimal quality of life (QoL) due to severe asthma symptoms and the allergen immunotherapy (ITA), which improves quality of life in such patients, is impossible to be started $[6,7]$.

Here, we present a case of severe persistent asthma responsive to omalizumab in a child with a history of unsuccessful immunotherapy.

\section{Case report}

A 17-year-old boy, non-smoker with a history of asthma and allergic rhinitis since childhood was presented to his primary care provider's office with persistent asthma that was limiting his activities such as his ability to sleep and exercise regularly. The skin test results revealed hypersensitivity to Dermatophagoides pteronyssimus and D. farine. In vitro specific IgE levels for D. pteronyssimus and D. farine were found to be $>100 \mathrm{kU} /$ ( (class 6). The patient with severe controlled asthma was under longterm anti-asthma therapy with moderate-to high-dose inhaled corticosteroids (ICS). This boy had qualified for subcutaneous specific immunotherapy (SCIT). During SCIT his asthma symptoms were often aggravated by upper respiratory infections and asthma exacerbations and the maintenance dose could not be reached and SCIT was discontinued. He had used his medications regularly but had had to attend the emergency department about 3 times a year. Despite 10 years of SCIT, no effect of immunotherapy was achieved (data from medical history from another outpatient clinic). During that time evidence of osteopenia was noted on a bone dual energy $X$-ray absorptiometry scan. At that time he was referred to our Department of Pediatrics and Allergy.

On presentation, boy, who weighs $65 \mathrm{~kg}$, was taking inhaled fluticasone/salmeterol 250/50 $\mu \mathrm{g}$ twice a day and oral montelukast $10 \mathrm{mg}$ every day. In the past year, he required salbutamol rescue approximately 3 or 4 times weekly and short-course oral corticosteroid therapy twice over the past year. Clinical findings revealed a decreased lung function with FEV forced expiratory volume in $1 \mathrm{~s}\left(\mathrm{FEV}_{1}\right)$ level at $74 \%$ of the predicted level before bronchodilation; after bronchodilation, the FEV was $88 \%$ of the predicted level. Fractional exhaled nitric oxide (FeNO) value was 80 ppb, other spirometric pa-

Address for correspondence: Prof. Iwona Stelmach MD, PhD, Department of Pediatrics and Allergy, N. Copernicus Hospital, 62 Pabianicka St, 93-513 Lodz, Poland, phone: +48 4268959 72, fax: +48 4268959 73, e-mail: alergol@kopernik.lodz.pl Received: 21.11.2013, accepted: 9.01.2014. 
rameters: $\mathrm{FEV}_{1} / \mathrm{FVC}$ - Tiffeneau index was $<80 \%$ of the predictive value, Rint was $220 \%$, sRaw 300\%. Boy had a total serum IgE of $922 \mathrm{kU} /$, specific IgE levels for D. pteronyssimus and $D$. farine were found in class 6 . The patient fulfilled the criteria for anti-lgE therapy and in February 2013, he was prescribed omalizumab $600 \mathrm{mg}$ every 2 weeks to treat persistent severe asthma symptoms. Four months later he had achieved better asthma control (no further need for rescue bronchodilator use) and a significant improvement of $\mathrm{FEV}_{1}$ up to $95 \%$ of the predicted value. After 16 weeks of treatment with omalizumab, the Asthma Control Questionnaire score had fallen from 2 to 0 points, and the asthma-related quality of life questionnaire (AQLQ) revealed a score of 7. Before starting the anti-lgE therapy, he had a severely impaired quality of life, with an AQLQ of 3 points (4 points' improvement).

In October 2013, boy is taking inhaled fluticasone $100 \mu \mathrm{g}$ twice a day and oral montelukast $10 \mathrm{mg}$ every day. More importantly, during therapy he was able to reduce his use of ICS and did not require any oral corticosteroids. He experienced an increase in his ability to exercise and noted no exacerbation of asthma symptoms.

\section{Discusion}

For many children with asthma, treatment falls short of achieving the best possible management of symptoms and results with side effects such as osteopenia in our patient. The IgE blockers such as omalizumab have demonstrated clear and well-tolerated benefits in the management of moderate-to-severe asthma in children, reducing acute exacerbation and the need for ICS, as well as improving score of QoL [8]. The treatment with omalizumab was clinically effective in our patient: the frequency of exacerbations and the number of hospitalizations were reduced, and there was a significant decrease in steroid use. Only 8 months of therapy led to a significant steroid sparing effect by omalizumab; we observed a 50\% reduction in the daily use of ICS in our patient. It is possible that in our patient SCIT could be successfully continued after the initiation of omalizumab therapy. Therefore, we recommend considering this therapeutic approach in a wide range of pediatric patients with severe asthma. There is an urgent need for a multicenter, randomized, placebo-controlled trial to measure the benefits of the combination of omalizumab and SCIT in reducing the dose of ICS required for severe asthma control in children.

\section{References}

1. Busse WW, Morgan WJ, Gergen PJ, et al. Randomized trial of omalizumab (anti-IgE) for asthma in inner-city children. N Engl J Med 2011; 364: 1005-15.
2. Steiss JO, Schmidt A, Nährlich L, et al. Immunoglobulin E monitoring and reduction of omalizumab therapy in children and adolescents. Allergy Asthma Proc 2012; 33: 77-81.

3. Thomson NC, Chaudhuri R. Omalizumab: clinical use for the management of asthma. Clin Med Insights Circ Respir Pulm Med 2012; 6: 27-40.

4. Lafeuille MH, Dean J, Zhang J, et al. Impact of omalizumab on emergency-department visits, hospitalizations, and corticosteroid use among patients with uncontrolled asthma. Ann Allergy Asthma Immunol 2012; 109: 59-64.

5. Jilcy M, Wilbert SA, Dipak C. Therapeutic options for severe asthma. Arch Med Sci 2012; 8: 589-97.

6. Brzyski P, Cichocka-Jarosz E, Tobiasz-Adamczyk B, et al. Theoretical validity and reliability of Vespide Quality of Life Questionnaire in Polish adolescents with Hymenoptera venom allergy. Postep Derm Alergol 2012; 29: 8-13.

7. Niedoszytko M, Majkowicz M, Chełmińska M, et al. Quality of life, anxiety, depression and satisfaction with life in patients treated with insect venom immunotherapy. Postep Derm Alergol 2012; 29: 74-9.

8. Hayden ML. Immunoglobulin E-mediated airway inflammation is active in most patients with asthma. J Am Acad Nurse Pract 2007; 19: 439-49. 